\title{
Leadership's Role In Effective Implementation Of School Discipline Policies
}

C. van Wyk, North-West University, South Africa

A. M. Pelser, North-West University, South Africa

\begin{abstract}
Discipline is an important aspect of the life of any school. Learning and teaching can only take place effectively in a disciplined environment. In South Africa, discipline policies might not have been effectively implemented due to inadequate sources, lack of commitment and training of school leaders. A qualitative research design was utilized for the investigation on which this article is based. The research consisted of two phases. First, group interviews were conducted with 27 B Ed Honours students; thereafter, individual interviews were conducted with a total of six students selected by purposive sampling. The results seem to suggest that the broader school community should be taken on board to ensure effective discipline policy implementation. The correct legal sources should furthermore be employed in the process of developing school policies. School leaders need thorough training for the development and implementation of discipline policies. Several measures are suggested for the effective introduction of disciplinary policies, among others, that school leadership should play a (more) active role; specifically the principals of schools should be willing to share their knowledge on the implementation of school disciplinary policies with other members of the school leadership.
\end{abstract}

Keywords: School Policy; School/Disciplinary Policy Implementation; School Leadership; Legislation; Empowerment; Communication

\section{INTRODUCTION}

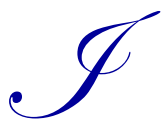

$\mathrm{t}$ is common knowledge that during the last two decades, the number and intensity of disciplinary problems in schools have markedly increased, as shown by a number of studies that concentrated on the nature and frequency of learner misbehavior (e.g., Irwin \& Nucci, 2004; Rossouw, 2003). The causes for such behavior have also been probed (see for example Wolhuter \& Steyn, 2003). In view of this, academics and practitioners have proposed a number of strategies that could be used to combat the negative effects of disciplinary problems in schools. Mestry, Moloi, and Mahomed (2007), for example, advocate a zero-tolerance approach; Du Plessis and Conley (2007), the whole-school approach; Lessing and Dreyer (2007) "endorse an approach of formative evaluation of training of teachers to implement positive disciplinary techniques"; and Joubert and Serakwane (2009) talk about the application of proactive discipline strategies. More recently, Mestry and Khumalo (2012) did a study on the perceptions and experiences of Student Governing Bodies in managing discipline in rural secondary schools through the design and enforcement of learner codes of conduct.

After the promulgation of the Constitution of the Republic of South Africa in 1996, learners became aware of their rights as human beings. Amongst others, corporal punishment was abolished without providing educators any alternative punishment measures. Educators seem to have become apprehensive because they saw the new official stipulations as a matter of 'sparing the rod and spoiling the child'. While teachers cast around for alternative methods of disciplining learners, respect for them began dwindling. School leadership, likewise, has been having difficulties to cope with learner misconduct. The establishing and implementation of sound discipline policies are seen by some as a measure that could assist leadership to cope with disciplinary problems. 


\section{Problem Statement}

The Department of Basic Education is mainly responsible for the development of the laws and regulations which serve as a guide for the formulation of disciplinary policies in schools. These laws and regulations are communicated to schools through the Provincial Education Departments. It then becomes the responsibility of the principal, school leadership, and the School Governing Body (SGB) to develop policies for their schools, based on the laws and regulations as stipulated by the department. In many cases, however, there seems to be a lack of communication between the Department and schools, as well as inadequate training of school leadership with respect to policy implementation. This has a snowball effect as principals seem to be guilty of not empowering other school leaders for the process of drafting of a school discipline policy and for the implementation thereof. All of this tends to result in inadequate discipline in the classroom which, it can be argued, might contribute, amongst other things, to a bad pass rate at the end of the school year.

The problem that was researched, the findings of which are reported below, was: How can leadership contribute to the effective developing and implementing of school discipline policies? The aim of the research was to find answers to this problem, and in the process, identify the problem areas that might impede effective development and implementation thereof.

\section{Theoretical Framework}

Policies and policy implementation can be viewed from different perspectives and it is difficult to provide generally accepted definitions of these concepts. A policy can be seen as an action program directed towards the accomplishment of some intended or desired set of goals (Hanekom, 1987). The Department of Education (DoE, 2007) stated that "a [school] policy consists of plans of action intended to influence and determine decisions, actions and other matters." It is made up of rules and regulations that serve as guidelines or plans that might be used to achieve certain objectives. As such, a policy provides the basis for the structures and organization of the school (DoE, 2007). A school policy can therefore be defined as an instrument that gives direction to the day-to-day operations of a school by guiding the behavior of educators, learners, and parents whilst clarifying the school's expectations, goals, and values.

School policies form part of and are based on macro policies such as the South African Schools Act of 1996, the South African Constitution of 1996, the National Education Policy Act of 1996, and education regulations that have been passed in terms of enabling legislation, as well as regulations and measures promulgated by provincial Education Departments. Provincial rules and regulations such as the Induction Guide for School Management Teams (NWP, 2007) provide further guidelines for the formulation of school policies such as learner and educator codes of conduct.

School discipline policies and rules are mainly used to regulate all aspects of behavior. They are not only supposed to prohibit misbehavior but rather to provide for a prohibition of specific negative occurrences. These policies are not merely intended to promote order but to assist learners to become followers and to encourage positive behavior. When comprehended in this way, discipline policies are indispensable in establishing and maintaining an environment conducive to learning as well as to create order, non-violence, and safety in the school.

It is imperative for schools not only to put such policies, like discipline, in place but also to continuously and consistently articulate the concomitant rules, expectations, and procedures. Hence, policies and rules must be clearly specified and communicated to learners and parents by means of newsletters, parents meetings, and information brochures. In this regard, Bray (2005) points out that in terms of the South African Schools Act of 1996, governing bodies of public schools have to adopt a Code of Conduct for learners which must be subjected to the Constitution of the Republic of South Africa (1996), the South African Schools Act (1996), and provincial legislation. Each school is responsible for developing their own Code of Conduct. Before a Code of Conduct may be drafted and adopted, the parents, learners, educators, and non-educators at a specific school should be consulted, as a Code of Conduct is a consensus document. A copy of the Code of Conduct must be submitted to all stakeholders; in this case, unity means power. 
This policy document deals in detail with learner discipline and prescribes disciplinary measures for learner misconduct. The Code of Conduct must be drafted and adopted in the correct manner, setting out the disciplinary rules applicable to all learners and formulating measures for punishment in case of misbehavior (Molefe, 2011).

An empirical investigation into the role of school leadership in the effective implementation of school disciplinary policies was launched on the basis of the foregoing theoretical framework. The following section contains a report on that part of the investigation.

\section{Empirical Investigation}

The aim of the investigation was to determine whether school disciplinary policies were being effectively implemented and to give a descriptive analysis of the participants' perceptions and their experiences in this regard.

An open-ended questionnaire was used as part of a qualitative research design to obtain the participants' perceptions about the relative importance of different aspects, which formed the foci of the study (Creswell, 2009).

First, a group interview was conducted with 27 B Ed Honours students at a South African university. These students were selected because they complied with the minimum admission requirements for the course of study and were all knowledgeable on the managerial and legislative issues targeted for this research. This selection formed the first step in the process of purposefully identifying and selecting six information-rich participants through purposive sampling.

During the next stage, the students were differentiated according to geographical regions. Only students from the Mafikeng area were selected because of their knowledge of the South African system. The Botswana students were therefore excluded from further participation. The second criterion for inclusion in the interviews had to do with the fact that only a limited number of participants were in leadership positions where they dealt on a daily basis with the implementation of discipline policies. The result of this procedure was a purposeful sample of six (6) students out of the total of 27.

The group and individual interviews were transcribed and the data analyzed according to pre-selected themes correlating with the research questions to ensure face validity (Creswell, 2012).

\section{FINDINGS}

All participants showed a good understanding of the importance of having good discipline policies and implementing them properly. One remarked, for example, "Policies are the legislatures or the laws and systems that you have in place as a school to make sure that things are running properly at the institution and that all decisions are based on policies." Another one stressed the importance of policy implementation by saying, "The implementation of policies is a very challenging exercise, and very interesting, because I don't think there would ever be any problem in South Africa if ever there was good implementation of policies."

The respondents viewed leadership as all those people who are officially or unofficially and directly or indirectly involved in school leadership. They are responsible for the leadership functions of guiding, controlling, and advising as well as for involvement in the "normal business" of the school. One respondent said, "School leadership are the people carrying out the policies, keeping order in the school, and regulating the working of the staff members in the school, and handling of the administration and discipline in school." Another added that the members of the Quality Learning, Teaching, and Curriculum (QLTC) committee that were appointed by the Minister of Education to ensure quality in learning, teaching, and the curriculum should also fulfill a leadership role with regard to the implementation of discipline policies. Based on the experience of the members of the school disciplinary committee, they should also participate in developing policies. A principal mentioned that it was of vital importance to involve all teachers' to "buy-in in this process." It was further regarded as critical that parents play an important role insofar as policy matters are concerned. One participant even said, "Parents have to sign, and to accept, it's like binding them to assist the school with the discipline and conduct of their children." Another one was of the opinion that "instead of taking only the SGB and SMT and teachers on board, learners should not be left behind and must also be involved in policy implementation." 
Participants also singled out the Code of Conduct as "a vehicle for getting discipline policies sorted out." They obviously had in mind that the Code can be used as a communication medium between the school and the rest of the community; in particular, parents. The Code of conduct was described as the guiding tool on how things should be done. The respondents viewed it as "an act of law which guides how a school or organization should be handled." A number of participants said that the Code of Conduct was well communicated to all stakeholders, including learners via the School Management Team (School Governing Body, Learner Representative Council LRC - and educators through regular meetings. One even commented that the Code of Conduct is made available in the form of a diary.

The policy directly dealing with the conduct of the learners (the Code of Conduct) is in the form of a diary. We have a school diary that is issued to each and every learner at the beginning of the year, so in that diary there's a copy of the school Code of Conduct, and a copy of all the other policies, like the terrain duty policy. The communication regarding information that we think parents need is contained in the diary.

A number of participants admitted that, although most teachers understand the functioning of the disciplinary system, some still practice corporal punishment despite it being abolished officially. They feel that this can only be rectified by providing better and more motivational training opportunities for teachers and parents. In this regard, one respondent replied, "I think if we can change the more punitive way of discipline and concentrate on the positive, maybe a rewarding system, our discipline can change a lot and even the attitude of learners can change."

\section{Explication of Recommendations}

Although there is a general perception amongst participants that policies are efficiently and even effectively implemented, it is clear that the number of and intensity of discipline problems has markedly increased in South African schools during the last decade. Cognizance must be taken of the fact that extreme forms of undisciplined behavior occur regularly in South Africa (Mouton, 2013). Participants are well aware that in the majority of schools, in the Mafikeng area, the culture of learning is threatened by actions such as substance abuse, bullying, rape, vandalism, and absenteeism. There is an understanding that good policy implementation should go a long way in solving these problems but also a feeling that amongst illiterate and previously (and current) impoverished communities, there is an underlying culture of non-compliance and that it would be very difficult to solve these profound issues by focusing on the school only.

Departmental officials, parents, teachers, academics, and other interested parties alike are involved on a daily basis to find solutions for the never-ending stream of disciplinary problems. This article is part of an academic investigation with the overriding research question, "What are leaders' roles in implementing discipline policies in schools?" The specific recommendations are presented under the headings The Department of Education, School Leadership, Parents and the Community, Learners and Teachers.

\section{The Department of Education}

As the key role player, the Department of Basic Education and the Provincial Department of Education, through their policymaking mechanisms, should ensure that the policies instituted are executed efficiently. This means that officials should be visible and performing well at ground level. Regular scheduled "working visits" should be paid to schools to determine, amongst other things, to what extent discipline policies have been implemented by the schools. Various aspects of policy implementation, such as the recording thereof and the degree to which other stakeholders than the principal and School Management Team have been involved, should be investigated.

The Provincial Department must also be brought to understand and to comply with their key role in empowerment and training as set out in the Schools Act (RSA, 1996, sect 19). It is not good enough to conduct investigations about the implementation of policies only. They have the responsibility to promote and provide training on different policies and the implementation thereof. Apart from personal meetings with school staff, training sessions, such as workshops, must be organized and presented. It is crucial to train SGB and SMT members 
as well so that they can participate meaningfully in policy implementation. Workshops for SGB members who are, for example, illiterate should even be presented in the local language.

\section{School Leadership}

It is important that individuals who occupy official positions as school leaders, such as principals, deputy principals, and heads of departments, as well as others who have leadership responsibilities from within and outside the school, such as those individuals who serve on the SGB, work together as teams. To get successful policy implementation in the long run, policies have to be co-owned by all parents and even by community members who have no direct interest in the school.

A prerequisite for agreement to participate in policy implementation is that all stakeholders should understand the origins and contents of policies. Discipline policies have to be aligned with national and provincial policies and must prohibit misbehavior but also provide for a prohibition of future negative occurrences. Leaders who are committed to effective policy implementation should realize that the non-implementation of school policies can have serious implications for the whole school community.

It is further recommended that the important role of principals within the participative or team approach may never be negated. The school principal is, in practice, still regarded as the primus inter pares (first among equals) and he/she will, especially in underprivileged communities, have to play an active role as leader in the SMT and SGB. It is through the principals' initiative in these committees that discipline policies are implemented. Despite the important role that principals play, they have to be reminded not to be autocratic or dominating. Policies can only be implemented after consultation and communication have taken place. As leaders, school principals must also be willing to share their knowledge with other members of the committees as well as with the community.

\section{Parents and the Community}

Against the background that in 1997 parents in South Africa were officially required to accept coresponsibility for the formulation of policies (Department of Education, 1997) and the reality that, during the interviews the participants indicated that, in large, parents do not show a responsible attitude towards their duties as parents, but even support their children in matters such as late-coming, absenteeism, and not doing their homework, it is recommended that parents be encouraged and even trained to take their responsibilities more seriously and to also understand the important role that the school plays in society.

Currently, there is an absence of individuals in the community who set good examples to children. In fact, many community members misuse or abuse children and get them involved in unlawful behavior. The broader school community should therefore be closely involved with the school, especially in discipline policy development matters.

It is also crucial to take key SGB and SMT members on board in a variety of ways. They could share their expertise with the school on technical and professional issues or represent the community on the SGB. Whichever way it is done, these participating community members will be fulfilling an important function that can be linked directly or indirectly to the implementation of policies, like the discipline policy.

It is also important to get the community to understand that the school can only operate as an institution that functions in a particular community and, as such, must reflect the values and aims of that community. Apart from taking the aspirations of individual parents into account in their functioning, community members, such as those who are employed by related government departments like Health and Safety, should especially be involved with the school in policy issues since they can see to it that critical aspects, such as care and safety, are emphasized in disciplinary policies.

Learners

A suitable environment should be created for learners in which they can feel safe to make contributions towards matters such as the discipline policy. Since the Code of Conduct affects learners directly, this is the most 
significant area in which they should be involved in policymaking. Subject to the SASA (RSA, 1996, sections 20 and 21), the SGB of a public school must inter alia adopt a code of conduct for learners of the school after consultation with them as well as with parents and educators. Their involvement is thus not a matter of choice, but is legally compelled.

Learners should not be kept in the dark on policy matters. They must be informed about new developments in this field so that they can look for practical ways to implement these policies that affect them directly.

\section{Teachers}

It is important to recommend that teachers' roles in the implementation of policies is not underestimated or undervalued. They may not be seen and treated as co-opted members when policies are implemented. With their participation, teachers can enhance a sense of fairness and trust in the school because they are usually seen to have the best interests of the children at heart. Furthermore, they are very closely linked to the "main business" of the school and understand discipline-related issues better than administrators. They are also in the best position to judge on the fairness of policies that will, at the same time, achieve improved learning outcomes.

Teachers must be seen as the main implementers of discipline policies; therefore, they should have an important say in deciding about discipline policies. They are professional people who have expert knowledge about instruction and learning, and discipline is interrelated with these activities. Responsibility for teaching and learning therefore goes hand in hand with responsibility for disciplinary matters. Documentary records, an incident book, and learners' portfolios are some of the documents that teachers could keep to enhance the process of policy implementation.

\section{GENERAL CONCLUSION}

Discipline is an important aspect of the life of any school, and learning and teaching can only take place effectively in a disciplined environment. In South Africa, discipline policies might not have been effectively implemented due to inadequate sources, lack of commitment, and training of school leaders. The effective implementation of discipline policies was thus addressed as the core problem in this study.

\section{AUTHOR INFORMATION}

Professor C. van Wyk, Professor in Educational Management, School of Leadership, North-West University, Private Bag X2046, Mmbatho, South Africa, 2735. E-mail: vanwyk.christo@ nwu.ac.za (Corresponding author)

Mrs. A. M. Pelser, Lecturer in Educational Management, School of Leadership, North-West University, Private Bag X2046, Mmbatho, South Africa, 2735. E-mail: Anna.Pelser@nwu.ac.za

\section{REFERENCES}

1. Botha, R. J. (2012). The role of the school principal in the South African school governing body: A case study of various members' perceptions. Journal for Social Science, 30(3), 263-271.

2. Bush, T. (2007). Educational leadership and management: Theory, policy and practice. South African Journal of Education, 27(3), 391-406.

3. Creswell, J. W. (2009). Research design: Qualitative, quantitative, and mixed methods approaches. Thousand Oaks: SAGE.

4. Creswell, J. W. (2012). Educational research: Planning, conducting and evaluating quantitative and qualitative research. Boston: Pearson Education Inc.

5. Department of Education (1997). Curriculum 2005: Lifelong learning for the 21 st century. Pretoria: Government Printer.

6. Du Plessis, P. J., \& Conley, L. (2007). Bullying in schools: Can we turn the tide? Paper presented at the International conference on Learner Discipline, Potchefstroom 2-4 April.

7. Hanekom, S. X. (1987). Public policy: Framework and instrument for action. Johannesburg: MacMillan. 
8. Irwin, L., \& Nucci, C. (2004). Perceptions of students' locus of control of discipline among pre-service and in-service teachers in multicultural classrooms. Intercultural Education, 15(1), 59-71.

9. Joubert, R., \& Serakwane, J. (2009). Establishing discipline in the contemporary classroom. Journal of Educational Studies, 8(2), 115-127.

10. Lessing, A. C., \& Dreyer, J. (2007). Every teacher's dream: Discipline is no longer a problem in South African schools! Paper presented at the International conference on Learner Discipline, Potchefstroom 2-4 April.

11. Mestry, R., \& Bisschoff, T. (2009). Financial school management explained. Pearson: Cape Town.

12. Mestry, R., \& Khumalo, J. (2012). Governing bodies and learner discipline: Managing rural schools in South Africa through a code of conduct. South African Journal of Education, 32, 97-110.

13. Mestry, R., Moloi, K. C., \& Mahomed, A. (2007). The efficacy of a zero-tolerance approach to managing learner discipline. Paper presented at the International conference on Learner Discipline, Potchefstroom 24 April.

14. Mncube, V. (2009). The perceptions of parents of their role in the democratic governance of schools in South Africa: Are they on board? South African Journal of Education, 29, 83-103.

15. Molefe, P. K. (2011). Managing classroom discipline in primary schools in the Ngaka Modiri Molema District. Mini-dissertation presented at the North-West University in fulfillment for the Masters Degree in Education.

16. Mouton, N., Louw, G. P., \& Strydom, G. (2013). Critical challenges of the South African school system. International Business \& Economics Research Journal, 1(12), 31-44.

17. National Department of Education (DoE). (1996). Changing management to manage change in education. Report of the task team on educational management development. Pretoria: Government Printers.

18. National Department of Education (DoE). (2000). School management teams: Managing and leading schools. Pretoria: CTP Book Printers.

19. North West Department of Education (NWP). (2007). Induction guide for school management teams. Mafikeng: Department of Education.

20. Republic of South Africa (RSA). (1996). South African Schools Act, No. 84 of 1996. Pretoria: Government Printers.

21. Rossouw, J. P. (2003). Learner discipline in South African public schools-a qualitative study. Koers, 68(4), 413-435.

22. Van der Mescht, H., \& Tyala, Z. (2008). School principals' perceptions of team management: A multiple case-study of secondary schools. South African Journal of Education, 28, 221-239.

23. Van der Walt, G., Van Niekerk, D., Doyle, M., Knipe, A., \& Du Toit, D. (2001). Managing for results in Government. Sandown: Heinemann.

24. Wolhuter, C. C., \& Steyn, S. C. (2003). Learner discipline at school: A comparative educational perspective. Koers, 68(4), 521-538. 
NOTES 